\title{
GD2 or HER2 targeting T cell engaging bispecific antibodies to treat osteosarcoma
}

\author{
Jeong A. Park and Nai-Kong V. Cheung ${ }^{*}$ (])
}

\begin{abstract}
Background: The cure rate for metastatic osteosarcoma has not substantially improved over the past decades. Clinical trials of anti-HER2 trastuzumab or anti-GD2 dinutuximab for metastatic or refractory osteosarcoma were not successful, and neither was immune checkpoint inhibitors (ICls).

Methods: We tested various target antigen expressions on osteosarcoma cell lines using flow cytometry and analyzed in vitro T cell engaging BsAb (T-BsAb)-dependent T cell-mediated cytotoxicity using $4-h^{51} \mathrm{Cr}$ release assay. We tested in vivo anti-tumor activities of T-BsAb targeting GD2 or HER2 in established osteosarcoma cell line or patient-

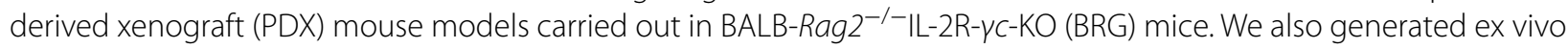
BsAb-armed T cells (EATs) and studied their tumor-suppressive effect against osteosarcoma xenografts. In order to improve the anti-tumor response, ICls, anti-human PD-1 (pembrolizumab) or anti-human PD-L1 (atezolizumab) antibodies were tested their synergy with GD2- or HER2-BsAb against osteosarcoma.

Results: GD2 and HER2 were chosen from a panel of surface markers on osteosarcoma cell lines and PDXs. Anti-GD2 BsAb or anti-HER2 BsAb exerted potent anti-tumor effect against osteosarcoma tumors in vitro and in vivo. T cells armed with anti-GD2-BsAb (GD2-EATs) or anti-HER2-BsAb (HER2-EATs) showed significant anti-tumor activities as well. Anti-PD-L1 combination treatment enhanced BsAb-armed T cell function in vivo and improved tumor control and survival of the mice, when given sequentially and continuously.
\end{abstract}

Conclusion: Anti-GD2 and anti-HER2 BsAbs were effective in controlling osteosarcoma. These data support the clinical investigation of GD2 and HER2 targeted T-BsAb treatment in combination with immune checkpoint inhibitors, particularly anti-PD-L1, in patients with osteosarcoma to improve their treatment outcome.

Keywords: Osteosarcoma, Immunotherapy, Bispecific antibody, Disialogangliosides, Human epidermal growth factor receptor-2, T cell arming, Ex vivo bispecific antibody-armed T cells (EATs), Programmed cell death protein 1 (PD-1), Programmed cell death-1 ligand 1(PD-L1)

\section{Introduction}

Osteosarcoma is the most common primary bone tumor in childhood and adolescence. With the introduction of multiagent chemotherapy, overall survival has improved to $60-70 \%$ [1]. However, survival rates have remained stagnant, and the prognosis for patients with metastatic or relapsed disease remains poor, with

\footnotetext{
*Correspondence: cheungn@mskcc.org
}

Department of Pediatrics, Memorial Sloan Kettering Cancer Center, 1275

York Ave, Box 170, New York, NY, USA a 5 -year overall survival rate of $20 \%$ [2-4]. Since the provocative observations of Dr. Coley on bacterial toxins inducing tumor regression [5], many immunotherapy attempts have been made in soft tissue and bone sarcomas, but success has been very limited $[6,7]$. The EURAMOS-1 clinical trial, which incorporated IFN- $\alpha 2 b$, failed to show the benefit [8], and also, antibody-based immunotherapies have not succeeded in improving outcome including trastuzumab or dinutuximab in clinical trials. Recent whole-genome sequencing (WGS) and molecular profiling studies of original author(s) and the source, provide a link to the Creative Commons licence, and indicate if changes were made. The images or other third party material in this article are included in the article's Creative Commons licence, unless indicated otherwise in a credit line to the material. If material is not included in the article's Creative Commons licence and your intended use is not permitted by statutory regulation or exceeds the permitted use, you will need to obtain permission directly from the copyright holder. To view a copy of this licence, visit http://creativecommons.org/licenses/by/4.0/. The Creative Commons Public Domain Dedication waiver (http://creativeco mmons.org/publicdomain/zero/1.0/) applies to the data made available in this article, unless otherwise stated in a credit line to the data. 
osteosarcoma have shown high levels of chromosome structural variations, rearrangements, and mutation clusters that result in significant disease heterogeneity but few clinically approachable alterations $[9,10]$. These studies have yielded insights into aberrant signaling pathways such as PI3K/mTOR, IGF, and Wnt [11-13], but the efficacy of these targeted therapies in unselected high-risk osteosarcoma patients has been limited [14, 15].

On the other hand, exploiting cytotoxic $\mathrm{T}$ cells against osteosarcoma remains a viable alternative. Yet, upregulation of programmed cell death-1 receptor (PD1) on $\mathrm{CD} 8(+)$ tumor-infiltrating lymphocytes (TILs) and interaction with its ligands (PD-L1 and PD-L2) in tumor cells are proven immune escape routes to impede anti-tumor activity of $\mathrm{T}$ cells against osteosarcoma $[16,17]$. Although immune checkpoint inhibitors (ICIs) have yet to demonstrate their benefit in patients with osteosarcoma (NCT02406781), blockade of PD-1 and PD-L1 interactions showed their potential to improve anti-tumor response in preclinical studies [18].

Here, we exploit bispecific antibody-directed $\mathrm{T}$ cell immunotherapy for osteosarcoma. We choose disialogangliosides (GD2) and human epidermal growth factor receptor-2 (HER2) as candidate target antigens because of their high expression across a number of osteosarcoma cell lines and their proven safety in IgGmediated treatment of neuroblastomas and breast cancers using IgG monoclonal antibodies, respectively. We previously described $\mathrm{T}$ cell engaging bispecific antibodies (T-BsAbs) using sequences of anti-CD3 (huOKT3) and anti-disialoganglioside [GD2] (hu3F8) or antiepidermal growth factor receptor-2 [HER2] (trastuzumab) antibody structured on IgG-[L]-scFv format with silenced Fc, exerting potent anti-tumor activities $[19,20]$. Anticipating $\mathrm{T}$ cells in cancer patients to be suboptimal in cell number and function [21], arming ex vivo expanded $\mathrm{T}$ cells with $\mathrm{T}$-BsAb should improve in vivo efficacy of BsAb treatment and minimize the risk of neurotoxicity or significant cytokine release syndrome (CRS), which was encountered by direct BsAb injection or CAR $T$ cell treatment [22-25]. Here, we test anti-tumor activities of anti-GD2-BsAb and antiHER2-BsAb against osteosarcoma in vitro and in vivo. In addition, we generate ex vivo armed T cells (EATs) using the anti-GD2-BsAb (GD2-EATs) or anti-HER2BsAb (HER2-EATs) and evaluate their antitumor efficacy. Furthermore, we incorporate immune checkpoint inhibitors (ICIs), anti-human PD-1 (pembrolizumab), or anti-human PD-L1 (atezolizumab) antibodies to GD2-EAT or HER2-EAT therapy and study the optimal inhibitor and combination schedule in order to improve their anti-tumor response.

\section{Methods}

\section{Cell lines}

Representative human osteosarcoma cell lines, 143B (ATCC Cat\# CRL-8304, RRID:CVCL_3477), U-2 OS (ATCC Cat\# HTB-96, RRID:CVCL_0042), MG-63 (ATCC Cat\# CRL-1427, RRID:CVCL_0426), HOS (ATCC Cat\# CRL-1543, RRID:CVCL_0312), and Saos-2 (ATCC Cat\# HTB-85, RRID:CVCL_0548), and osteoblast cell line, hFOB 1.19 (ATCC Cat\# CRL-11372, RRID:CVCL_3708), were purchased from ATCC (Manassa VA). All cells were authenticated by short tandem repeats profiling using PowerPlex 1.2 System (Promega, Cat\# DC8942), and periodically tested for mycoplasma infection using a commercial kit (Lonza, Cat\# LT07-318). The cells were cultured in RPMI1640 (Sigma) supplemented with $10 \%$ heat-inactivated fetal bovine serum (FBS, Life Technologies) at $37{ }^{\circ} \mathrm{C}$ in a $5 \%$ $\mathrm{CO}_{2}$ humidified incubator.

\section{Flow cytometry}

For flow cytometric analysis of antigen expression by human osteosarcoma cell lines, cells were harvested, and cell viability was determined. $1 \times 10^{6}$ cells were stained with $1 \mu \mathrm{g}$ of antigen specific mAbs in a total volume of $100 \mu \mathrm{L}$ for $30 \mathrm{~min}$ at $4{ }^{\circ} \mathrm{C}$. Anti-CD20 chimeric $\mathrm{mAb}$, rituximab, or mouse IgG1 monoclonal antibody was used as isotype control. After washing with PBS, cells were re-incubated with $0.1 \mu \mathrm{g}$ PE-conjugated goat anti-human IgG Ab (SouthernBiotech Cat\# 2040-09, RRID:AB_2795648). For each sample, 20,000 live cells were analyzed using a BD FACS Calibur TM (BD Biosciences, Heidelberg, Germany). Data were analyzed with FlowJo V10 software (FlowJo, RRID:SCR_008520) using geometric mean fluorescence intensity (MFI). The MFI for isotype control antibody was set to 5 , and the MFIs for antibody binding were normalized based on isotype control.

\section{Effector cell preparation}

Effector peripheral blood mononuclear cells (PBMC) were separated by Ficoll from buffy coats purchased from the New York Blood Center. T cells were purified from PBMC using Pan $\mathrm{T}$ cell isolation kit (Miltenyi Biotec, Cat\# 130096535). These $\mathrm{T}$ cells were activated by CD3/ CD28 Dynabeads (Gibco ${ }^{\text {TM }}$, Cat\# 11132D) for 7 to 14 days in the presence of $30 \mathrm{IU} / \mathrm{mL}$ of IL-2 according to manufacturer's protocol. PBMCs and ATCs were analyzed by FACS for their proportion of CD3(+), CD4(+), CD8(+), and CD56(+) cells.

\section{Cytotoxicity assays $\left({ }^{51}\right.$ chromium release assay)}

Antibody-dependent $\mathrm{T}$ cell-mediated cytotoxicity (ADTC) was assessed by ${ }^{51} \mathrm{Cr}$ release assay, and $\mathrm{EC}_{50}$ was 
calculated using Sigma Plot software. Tumor cells were labeled with sodium ${ }^{51} \mathrm{Cr}$ chromate (Amersham, Arlington Height, IL) at $100 \mathrm{mCi} / 10^{6}$ cells at $37^{\circ} \mathrm{C}$ for $1 \mathrm{~h}$. After two washes, tumor cells were plated in a 96-well plate before mixing with activated T cells (ATCs) at decreasing concentrations of T-BsAb. Effector-to-target cell ratio (ET ratio) was 10:1, and cytotoxicity was analyzed after incubation at $37^{\circ} \mathrm{C}$ for $4 \mathrm{~h}$. The released ${ }^{51} \mathrm{Cr}$ was measured by a gamma counter (Packed Instrument, Downers Grove, IL). Percentage of specific lysis was calculated using the formula: 100\% (experimental cpmbackground $\mathrm{cpm}) /($ total $\mathrm{cpm}$-background $\mathrm{cpm}$ ), where $\mathrm{cpm}$ represented counts per minute of ${ }^{51} \mathrm{Cr}$ released. Total release of ${ }^{51} \mathrm{Cr}$ was assessed by lysis with $10 \%$ SDS (Sigma, St Louis, Mo, Cat\# 71736), and background release was measured in the absence of effector cells and antibodies.

\section{Antibodies}

For each BsAb, scFv of huOKT3 was fused to the C-terminus of the light chain of human IgG1 via a C-terminal (G4S)3 linker [26]. N297A and K322A on Fc were generated with site-directed mutagenesis via primer extension in polymerase chain reactions [27]. The nucleotide sequence encoding each BsAb was synthesized by GenScript and was subcloned into a mammalian expression vector. Each BsAb was produced using Expi293 ${ }^{\mathrm{TM}}$ expression system (Thermo Fisher Scientific, Cat\# A14635) separately. BsAbs were purified with protein A affinity column chromatography. GD2-BsAb was linked to the carboxyl end of the anti-GD2 hu3F8 IgG1 light chain [19], and HER2-BsAb linked to the anti-HER2 trastuzumab IgG1 light chain [20]. Anti-CD33/anti-CD3 BsAb or anti-GPA33/anti-CD3 BsAb was used as a control BsAb for ADTC assay and in vivo animal experiments $[28,29]$. The other BsAbs used in this study were previously described (US patent\# 62/896,415). The purity of BsAbs was evaluated by size-exclusion high-performance liquid chromatography (SE-HPLC), and they had high levels of purity (>90\%). The BsAbs remained stable by SDS-PAGE and SEC-HPLC after multiple freeze-thaw cycles. The biochemical data of BsAbs used are summarized in Additional file 1: Table S1.

\section{T cell arming}

Ex vivo activated $T$ cells were harvested between day 7 and day 14 and armed with each BsAb for 20 min at room temperature. After incubation, the $\mathrm{T}$ cells were washed with PBS twice. Properties of ex vivo bispecific antibodyarmed $\mathrm{T}$ cells (EATs) were tested for cell surface density of BsAb using flow cytometry and in vitro cytotoxicity against target antigens. BsAb bound to T cell was measured with anti-idiotype antibody for GD2-EATs and anti-human IgG Fc antibody (BioLegend, Cat\# 409303, RRID:AB_10900424) for HER2-EATs.

\section{In vivo experiments}

All animal experiments were approved by the Memorial Sloan Kettering's Institutional Animal Care and Use Committee (IACUC) and were executed according to the IACUC guidelines. For in vivo experiments, BALB-Rag $2^{-} /{ }^{-}$IL-2R- $\gamma c-$ KO (BRG) mice (Taconic Biosciences) were used [30]. In vivo experiments were performed in 6-10-week-old male mice. Tumor cells were suspended in Matrigel (Corning Corp, Tewksbury MA) and implanted in the flank of BRG mice. Besides tumor cell line xenografts, 3 different patient-derived tumor xenografts (PDXs) positive for both GD2 and HER2 were established from fresh surgical specimens with MSKCC IRB approval. Tumor size was measured using TM900 scanner (Piera, Brussels, BE), and treatment was started when tumor size reached $100 \mathrm{~mm}^{3}$. Before treatment, mice were randomly assigned to each group. Tumor growth curves and overall survival were analyzed, and the overall survival was defined as the time from the start of treatment to when tumor volume reached $2000 \mathrm{~mm}^{3}$. To define well-being of mice, $\mathrm{CBC}$ analyses, changes in body weight, general activity, physical appearance, and GVHD scoring were monitored. All animal experiments were repeated twice more with different donor's $\mathrm{T}$ cells to ensure that our results were reliable.

\section{Cytokine release assays}

Human Th1 cell-released cytokines were analyzed after EAT injection using LEGENDplexTM Human Th1 Panel (Biolegend, Cat\# 741035). Five human $\mathrm{T}$ cell cytokines including IL-2, IL-6, IL-10, IFN- $\gamma$, and TNF- $\alpha$ were analyzed using mouse serum $4 \mathrm{~h}, 12 \mathrm{~h}$, and $24 \mathrm{~h}$ after EAT injection.

Single cell suspension for flow cytometry analysis of tumor Surgically resected tumor samples were transported in $\mathrm{PBS}$ at room temperature and transferred to $50-\mathrm{mL}$ conical tubes with warm medium (RPMI $1640+10 \%$ FBS). Tissues were dissociated to $1-3 \mathrm{~mm}^{3}$ pieces using scalpels with blade and followed by 1-h enzymatic dissociation using 20X Collagenase II (ThermoFisher Scientific, Cat\# 17101015), 100X DNase I (ThermoFisher Scientific, Cat\# EN0521). Samples were filtered with $70-\mu \mathrm{m}$ and 40- $\mu \mathrm{m}$ cell strainers, and red blood cells were eliminated using ACK lysis buffer (ThermoFisher Scientific, Cat\# A1049201). After centrifugation, cells were resuspended in warm medium and counted to quantify viable cells using Trypan blue. 


\section{Flow cytometry of blood and tumor}

Peripheral blood and tumors were collected and analyzed by flow cytometry. Anti-human antibodies against CD3 (BioLegend, Cat\# 300308, RRID:AB_314044), CD4 (BioLegend, Cat\# 357410, RRID:AB_2565662), CD8 (BioLegend, Cat\# 300912, RRID:AB_314116), and CD45 (BioLegend, Cat\# 304012, RRID:AB_314400) were used to define $\mathrm{T}$ cell engraftment and subpopulation, and anti-human PD-1 (BioLegend Cat\# 367410, RRID:AB_2566680) and PD-L1 antibodies (BioLegend Cat\# 329706, RRID:AB_940368) were used to quantify their expression by $\mathrm{T}$ cells and osteosarcoma tumor cells. Stained cells were processed with BD LSRFORTESSA (BD Biosciences, Heidelberg, Germany) and analyzed with FlowJo software (FlowJo, LLC, Ashland, OR).

\section{Immunohistochemical (IHC) staining}

Formalin-fixed paraffin-embedded tumor sections were made, and immunohistochemical (IHC) staining for human CD3, CD4, and CD8 T cells was done to confirm $\mathrm{T}$ cell infiltration inside tumors. The IHC staining was performed at Molecular Cytology Core Facility of MSKCC using Discovery XT processor (Ventana Medical Systems). Paraffin-embedded tumor sections were deparaffinized with EZPrep buffer (Ventana Medical Systems), antigen retrieval was performed with CC1 buffer (Ventana Medical Systems), and sections were blocked for 30 min with background buffer solution (Innovex). AntiCD3 (Agilent, Cat\# A0452, RRID:AB_2335677, $1.2 \mu \mathrm{g}$ / $\mathrm{mL}$ ), anti-CD4 (Ventana Medical Systems Cat\# 790-4423, RRID:AB_2335982, $0.5 \mu \mathrm{g} / \mathrm{mL}$ ), and anti-CD8 (Ventana Medical Systems Cat\# 790-4460, RRID:AB_2335985, $0.07 \mu \mathrm{g} / \mathrm{mL}$ ) were applied, and sections were incubated for $5 \mathrm{~h}$, followed by 60-min incubation with biotinylated goat anti-rabbit IgG (Vector Laboratories, Cat\# BA-1000, RRID:AB_2313606) at 1:200 dilution. For PD-L1 staining, the sections were pre-treated with Leica Bond ER2 Buffer (Leica Biosystems) for $20 \mathrm{~min}$ at $100{ }^{\circ} \mathrm{C}$, stained with PD-L1 rabbit monoclonal antibody (cell signaling, Cat\# 29122, $2.5 \mathrm{mg} / \mathrm{mL}$ ) for $1 \mathrm{~h}$ on Leica Bond RX (Leica Biosystems). Control antibody staining was done with biotinylated goat anti-rat IgG (Vector Laboratories, Cat\# BA-9400, RRID:AB_2336202). All images were captured from tumor sections using Nikon ECLIPSE Ni-U microscope and NIS-Elements 4.0 imaging software. Antigenpositive cells were counted with Qupath 0.1.2.

\section{GD2 expression by IHC}

Fresh-frozen tumor sections were made using TissueTek OCT (Miles Laboratories, Inc, Elkhart, IN) with liquid nitrogen and stored at $-80{ }^{\circ} \mathrm{C}$. The tumor sections were stained with mouse IgG3 mAb 3F8 as previously described [31]. Stained slides were captured using a
Nikon ECLIPSE Ni-U microscope and analyzed, and the tissue staining intensity was compared with positive and negative controls and scored from 0 to 4 according to two components: staining intensity and percentage of positive cells. Each sample was assessed and graded by two independent observers.

\section{Statistics}

In vivo anti-tumor effect and cytokine release analyses were compared using area under curve (AUC) and survival curves calculated using GraphPad Prism 8.0. Differences between samples indicated in the figures were tested for statistical significance by two-tailed Student's t-test for two sets of data, while one-way ANOVA was used to among three or more sets of data. All statistical analyses were performed using GraphPad Prism V.8.0 for Windows (GraphPad Prism, RRID:SCR_002798). $P<0.05$ was considered statistically significant. Asterisks indicate that the experimental $P$-value is statistically significantly different from the associated controls at $* P<0.05$; ** $P<0.01$; *** $P<0.001$, **** $P<0.0001$.

\section{Results}

GD2 and/or HER2 was overexpressed on majority of osteosarcoma cell lines

To identify potential therapeutic targets for osteosarcoma, we conducted a literature review and assessed the expression of surface target antigens, GD2, GD3, HER2, B7H3 (CD276), high molecular weight melanoma antigen (HMW-M), gene name chondroitin-sulfate proteoglycan-4 (CSPG4), glycoprotein A33 (GPA33), L1 cell adhesion molecule (L1CAM), glypican-3 (GPC-3), Lewis $\mathrm{Y}$, prostate-specific antigen (PSA), Globo $\mathrm{H}$, interleukin 11 receptor- $\alpha$ (IL-11R $\alpha$ ), PD-L1, prostate-specific membrane antigen (PSMA), and insulin-like growth factor 2 receptor (IGF2R), reported to be overexpressed by osteosarcoma [32-35]. Surface antigen expression levels were semiquantitated by flow cytometric analysis and normalized with the geometric mean fluorescence intensity (MFI) of a control antibody (Table 1 and Additional file 2: Fig. S1). The majority of osteosarcoma cell lines overexpressed GD2 and/or HER2 antigen on their cell surface. However, their MFIs for GD2 or HER2 staining were generally much lower than those for GD2(+) neuroblastoma cell lines, or HER2 $(+)$ breast cancer cell lines, respectively. Based on their MFIs, GD2, HER2, B7H3, CSPG4, L1CAM (CD171), and Lewis Y were chosen as tumor targets for further in vitro screening.

\section{GD2-BsAb and HER2-BsAb exerted strong cytotoxicity against osteosarcoma cell lines in vitro}

Antibody-dependent $\mathrm{T}$ cell-mediated cytotoxicity (ADTC) assay using activated T cells (E:T ratio of 10:1) 


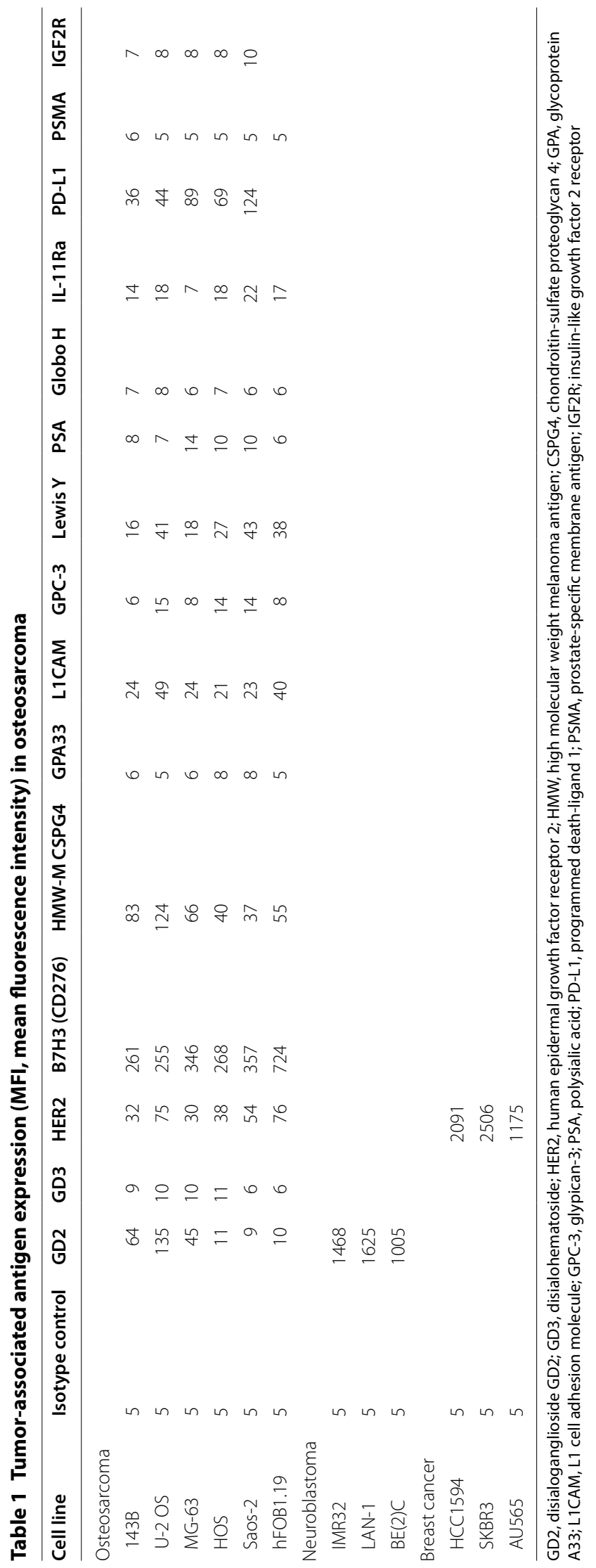


in the presence of decreasing concentrations of BsAbs [1 $\mu \mathrm{g} / \mathrm{mL}(5 \mathrm{nM})$ and serial tenfold dilutions] was performed against a panel of osteosarcoma cell line. All tested BsAbs were made using the IgG-[L]-scFv format with silenced Fc, and anti-CD33/anti-CD3 BsAb was used for control Ab [29]. Among them, anti-GD2 BsAb (GD2-BsAb)and anti-HER2-BsAb (HER2-BsAb) showed the most potent ADTC against the panel of osteosarcoma cell lines (Table 2). For GD2-BsAb, cytotoxicity was robust (EC50 of 0.2 to $0.5 \mathrm{pM}$ ) for GD2(+) osteosarcoma cell lines (143B, U-2 OS, and MG-63), where maximal killing was observed between 5 and 500 pM (Fig. 1a). HER2-BsAb also mediated potent ADTC against most of the osteosarcoma cell lines which were HER2-positive (143B, U-2 OS, MG-63, HOS, and Saos-2) and against hFOB1.19, with maximal cytotoxicity at 5 to $500 \mathrm{pM}$. Anti-tumor potency of each BsAb [EC50 (a measure of in vitro sensitivity to ADTC)] was inversely correlated with MFIs of each target antigen. Although B7H3, L1CAM, CSPG4, and Lewis Y were also overexpressed by some osteosarcoma cell lines, the ADTC potency of their respective BsAb was much weaker than GD2-BsAb or HER2-BsAb. Based on these findings, the targets GD2 and HER2 were chosen for further in-depth $T$ cell-based immunotherapy studies.

GD2-BsAb and HER2-BsAb showed potent anti-tumor activities against osteosarcoma xenografts

Next, we tested in vivo anti-tumor response of GD2$\mathrm{BsAb}$ and HER2-BsAb against osteosarcoma xenografts (Fig. 1b). In the first xenografted mouse model, osteo- reproduced in a second tumor model where PBMCs were administered weekly iv instead of sc. Both GD2-BsAb and HER2-BsAb significantly suppressed tumor growth compared to controls $(P=0.0025$ for GD2-BsAb and $P=0.0248$ for HER2-BsAb, respectively).

To confirm this anti-tumor effect, $\mathrm{T}$ cell infiltration inside tumors was studied using IHC staining after treatment of GD2-BsAb and HER2-BsAb with iv PBMCs. CD3(+) TILs were detected in both GD2-BsAb- and HER2-BsAb-treated tumors (Fig. 1c), but not in tumors treated with control BsAb. Serial $\mathrm{T}$ cell infiltration was also investigated by staining tumors on days $6,9,16$, 23, and 30 post-treatment (Fig. 1d). While TILs showed CD4(+) T cell predominance on day 9, CD8 (+) T cells became predominant at later time points (day 23 and day 30).

\section{Adoptive T cell immunotherapy using ex vivo armed T cells (EATs) carrying GD2-BsAb or HER2-BsAb was effective}

To optimize BsAb treatment, ex vivo GD2-BsAb-armed T cells (GD2-EATs) and HER2-BsAb-armed T cells (HER2EATs) were generated, and we assessed their safety and efficacy for the treatment of osteosarcoma. Both EATs showed stable BsAb binding (Additional file 2: Fig. S2A) and effective tumor cell killing against osteosarcoma cell lines over a range of $\mathrm{E}: \mathrm{T}$ ratios and antibody doses (Additional file 2: Fig. S2B). Maximum killing was observed between $0.05 \mu \mathrm{g}$ and $5 \mu \mathrm{g} / 10^{6} \mathrm{~T}$ cells of BsAb-arming concentration. To test the stability of EATs, GD2-EATs and HER2-EATs were incubated at $4{ }^{\circ} \mathrm{C}$ for $72 \mathrm{~h}$, and the MFIs of each BsAb were measured using anti-human IgG

Table 2 In vitro sensitivities (EC50, pM) to target antigen-specific bispecific antibodies in osteosarcoma cell lines

\begin{tabular}{|c|c|c|c|c|c|c|}
\hline & GD2 & HER2 & B7H3 & CSPG4 & L1CAM & Lewis Y \\
\hline \multicolumn{7}{|c|}{ Osteosarcoma } \\
\hline $143 B$ & 0.2 & 10 & 130 & 454 & 329 & 1440 \\
\hline U-2 OS & 0.5 & 11 & 150 & 116 & 92 & 692 \\
\hline MG-63 & 0.4 & 8 & 109 & 558 & 397 & 4655 \\
\hline $\mathrm{HOS}$ & 3906 & 10 & 274 & 645 & 158 & 312 \\
\hline Saos-2 & $>5000$ & 18 & 120 & 500 & 229 & 468 \\
\hline \multicolumn{7}{|l|}{ Osteoblast } \\
\hline hFOB 1.19 & $>5000$ & 69 & 126 & 498 & 121 & 600 \\
\hline
\end{tabular}

sarcoma 143B tumor cells were mixed with PBMCs and implanted subcutaneously (sc) into mice. Tumors were treated with intravenous (iv) GD2-BsAb or HER2-BsAb twice per week for 4 weeks. GD2-BsAb and HER2-BsAb suppressed osteosarcoma growth compared to negative controls (GPA33-BsAb) $(P=0.0005$ for GD2-BsAb and $P=0.10$ for HER2-BsAb, respectively). This finding was
Fc antibody at different time points. Both GD2-EATs and HER2-EATs showed stable BsAb binding over time, and their MFIs after $72 \mathrm{~h}$ have maintained $80 \%$ of the levels of EATs at first (Additional file 2: Fig. S2C).

To address in vivo anti-tumor effect and safety of EATs, we treated 143B xenografts with $2 \times 10^{7}$ of EATs armed with increasing concentrations ( 1 to $100 \mu \mathrm{g}$ ) of 
(See figure on next page.)

Fig. 1 GD2-BsAb and HER2-BsAb exerted strong cytotoxicity against osteosarcoma. a Antibody-dependent T cell-mediated cytotoxicity (ADTC) was analyzed by ${ }^{51} \mathrm{Cr}$ release assay using activated T cells (ET ratio, 10 to 1) at decreasing concentrations of BsAb in an osteosarcoma cell line panel. Cytotoxicity was compared to control BsAb with T cells and each BsAb alone. $\mathbf{b}$ In vivo anti-tumor activity of GD2-BsAb and HER2-BsAb against osteosarcoma. c Immunohistochemical (IHC) staining of tumor-infiltrating lymphocytes. Tumors were harvested on day 30 post-treatment and stained with anti-human CD3 antibody ( $\times 200)$. $\mathbf{d} 1 \mathrm{HC}$ staining of tumors by anti-human CD4 and anti-human CD8 antibody ( $\times 200)$ following treatment with iv PBMC and iv GD2-BsAb

GD2-BsAb or HER2-BsAb (Fig. 2a). In vivo cytokine levels were analyzed following EATs or unarmed T cells injection (Additional file 2: Fig.S3). Although high-dose GD2-EATs $\left(100 \mu \mathrm{g} / 2 \times 10^{7}\right.$ cells $)$ released higher levels of IL- 2 and TNF- $\alpha$ compared to controls, TH1 cell cytokines (except IFN- $\gamma$ ) were not significantly elevated after EATs injection. Only IFN- $\gamma$ levels were significantly elevated in GD2-EAT-treated mice compared to controls. Most mice maintained their body weight and activity and did not exhibit toxicity during the followup period. Tumor growth was significantly suppressed over a range of BsAb-arming concentrations (1 to $100 \mu \mathrm{g}$ of $\mathrm{BsAb} / 2 \times 10^{7}$ cells) in contrast to the control group $\left(2 \times 10^{7}\right.$ of unarmed T cells $)(P<0.0001)$. This potent anti-tumor effect of GD2-EATs and HER2-EATs was confirmed in multiple osteosarcoma PDX mouse models (Fig. 2b). GD2-EATs and HER2-EATs successfully regressed multiple osteosarcoma PDX tumors, leading to significantly improved survival compared to negative controls [no treatment, unarmed T cells, or control EATs (T cells armed with GPA33-BsAb)], $(P<0.0001)$.

\section{Combinational treatment of immune checkpoint inhibitors and GD2- or HER2-bispecific antibody-armed T cell immunotherapy}

Although GD2-BsAb and HER2-BsAb recruited substantial numbers of $\mathrm{T}$ cells into tumors and successfully suppressed tumor growth compared to controls, some tumors showed resistance or relapsed following the initial response. TILs showed predominance of CD8(+) T cells, and the majority of which expressed PD-1 on their surface (Fig. 3a). Circulating CD3(+) T cells in peripheral blood on days $6,9,16$, and 23 post-treatment showed gradual increase of PD-1 expression from less than 5\% to over $75 \%$ after treatment with GD2-BsAb, being different from controls (iv PBMCs only) which showed a more sudden surge of circulating T cells and PD-1 expression on day 23 post-treatment, which attributed to human hematopoietic and lymphoid cell engraftment and xenogeneic graft-versus-host disease (Fig. 3b) [36, 37]. In addition to PD-1 expression on $\mathrm{T}$ cells, osteosarcoma xenografts were PD-L1-positive by IHC staining and FACS analyses, and PD-L1 expression was upregulated following BsAb treatment (Fig. 3c).

\section{PD-L1 blockade augmented anti-tumor activity of EAT therapy}

To test whether PD-1 blockades can overcome $\mathrm{T}$ cell exhaustion related to treatment resistance, we combined anti-PD-1 (pembrolizumab) or anti-PD-L1 (atezolizumab) monoclonal antibody and GD2-EATs or HER2-EATs and evaluated their synergy in osteosarcoma cell line xenograft mouse model (Fig. 4a). GD2EATs or HER2-EATs were administered twice a week for 3 weeks, and iv anti-PD-1 or anti-PD-L1 was started on day 9 post-EAT therapy and given twice per week for 3 weeks, based on the anticipated PD-1 upregulation in $\mathrm{T}$ cells by day 9 (Fig. 3b). Anti-PD-L1 plus GD2-EATs or HER2-EATs improved tumor control compared to EATs alone $(P=0.0257$ for GD2-EATs and $P=0.0374$ for HER2-EATs), while combination with anti-PD-1 failed to improve the anti-tumor response compared to GD2EATs or HER2-EATs alone $(P=0.1969$ and $P=0.7894$, respectively). Anti-PD-L1 combination resulted in greater frequencies of $\mathrm{T}$ cells in tumors compared to GD2-EATs or HER2-EATs alone, whereas anti-PD-1 combination did not (Fig. 4b). Interestingly, GD2-EATs and GD2-EATs plus anti-PD-L1 appeared to eliminate GD2 $2^{\text {high }}$ tumor cells while leaving GD2 ${ }^{\text {low }}$ tumor cells behind (by IHC), but GD2-EATs plus anti-PD-1 did not show such effects (Fig. 4c), consistent with the lack of benefit from anti-PD-1 combination with EAT therapy.

\section{Timing of anti-PD-L1 during GD2-EAT therapy affected anti-tumor immune response}

Given the upregulation of PD-1/PD-L1 pathway following BsAb treatment, we tested three different time schedules of PD-1 blockades with GD2-EAT therapy (Fig. 5a). GD2-EATs were given three times per week for 2 weeks. Six doses of anti-PD-1 or anti-PD-L1 were given either (1) concurrently (concurrent therapy, CT), (2) sequentially after 6 doses of EATs (sequential therapy, ST), or (3) sequentially continuous way [additional 6 more doses of PD-1 blockades post-ST (sequentially continuous therapy, SCT)]. Combination with anti-PD-1 had no benefit, either using CT, ST or SCT regimens when compared to GD2-EATs alone. CT of anti-PD-L1 also failed to improve the anti-tumor response of GD2-EATs. However, anti-PD-L1 given as ST slowed the tumor growth, and SCT of anti-PD-L1 significantly suppressed tumor 


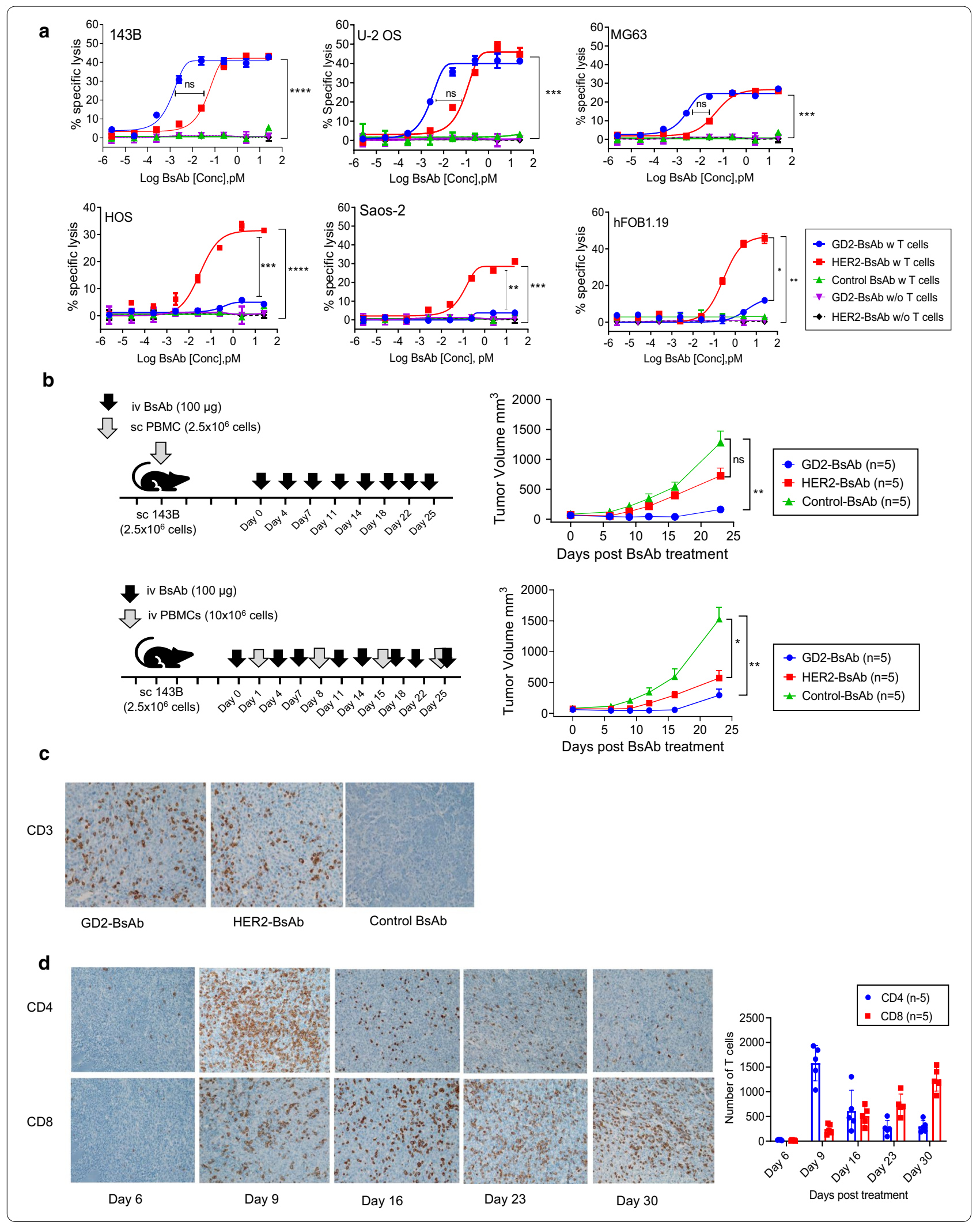


a iv EATs $\left(2 \times 10^{7}\right.$ cells $)$
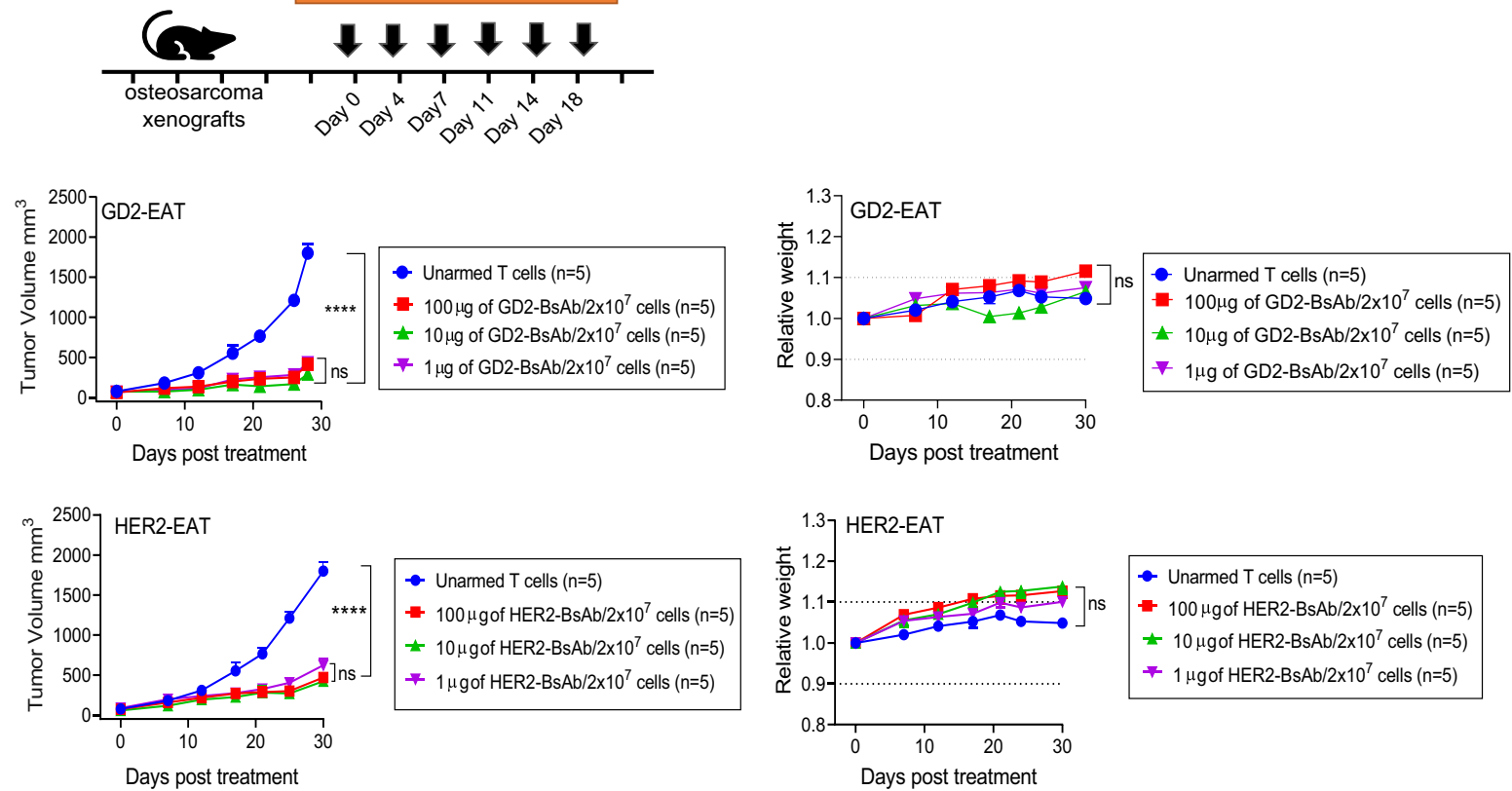

b OSOS1B PDX
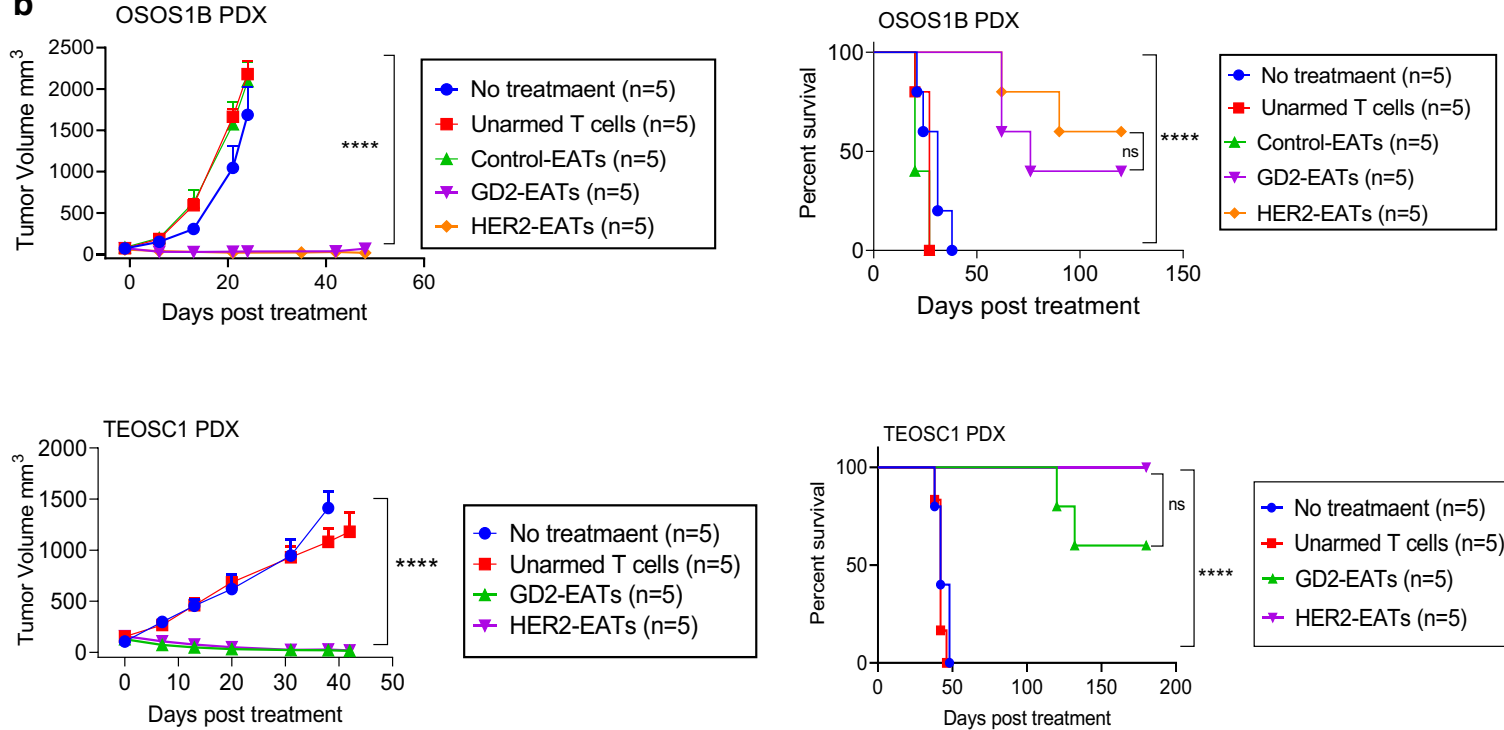

- No treatmaent $(\mathrm{n}=5)$

- Unarmed T cells $(n=5)$

$\star$ GD2-EATs $(n=5)$

$* \operatorname{HER} 2-\mathrm{EATS}(\mathrm{n}=5)$
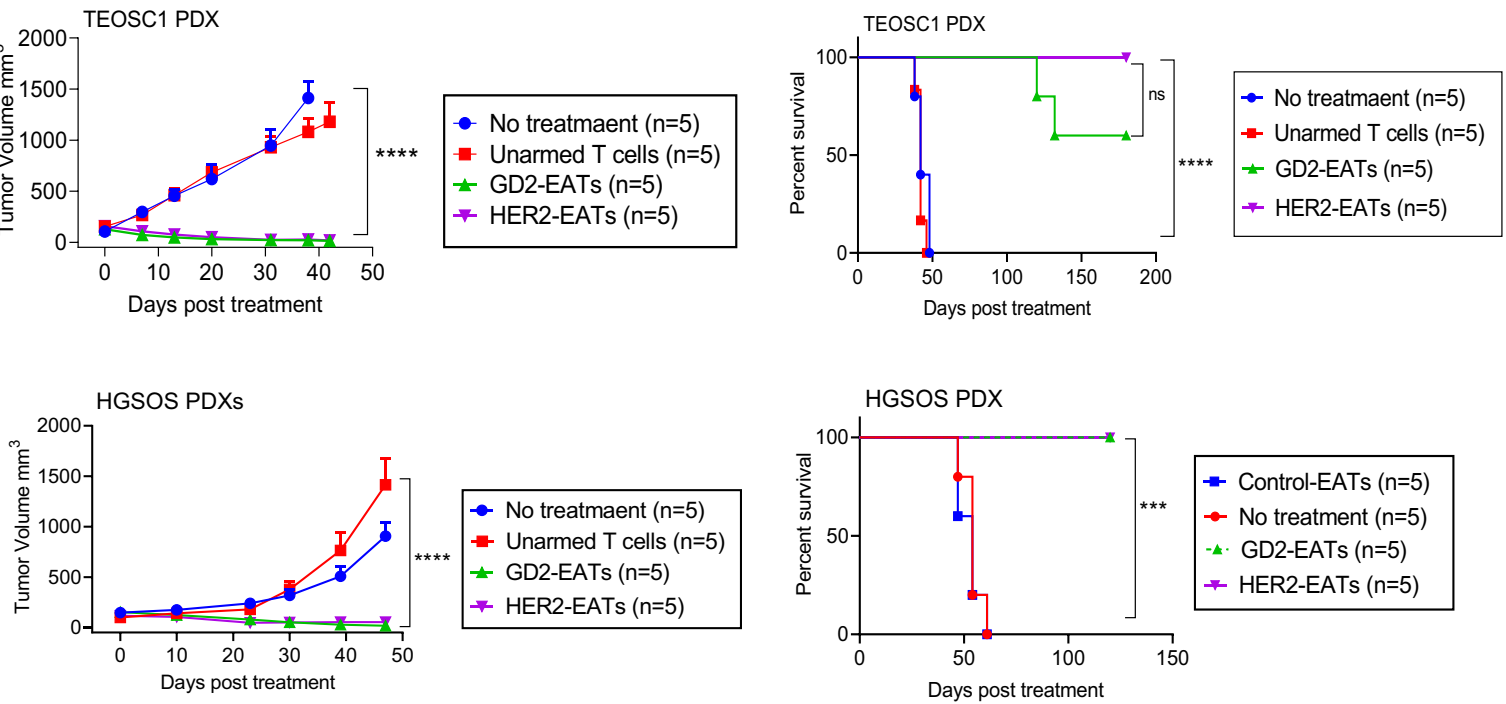

Fig. 2 In vivo anti-tumor activity of ex vivo GD2-BsAb or HER2-BsAb-armed T cells (EATs). a Anti-tumor activities of GD2-EATs and HER2-EATs were tested over a range of BsAb arming concentrations in vivo. $\mathbf{b}$ GD2-EATs ( $10 \mu \mathrm{g}$ of GD2-BsAb/2 $\times 10^{7}$ cells) and HER2-EATs ( $10 \mu \mathrm{g}$ of HER2-BsAb/2 $\times 10^{7}$ cells) exerted a potent anti-tumor effect against a variety of osteosarcoma PDXs without significant toxicity, improving survival 


\section{(See figure on next page.)}

Fig. 3 PD-1 and PD-L1 expression by T cells and osteosarcoma cell line xenografts. a Flow cytometry analysis of PD-1 expression on tumor-infiltrating lymphocytes (TILs) in osteosarcoma 143B cell line xenografts on day 35 post-GD2-BsAb treatment. b Flow cytometry analyses of human CD3(+) T cells and human PD-1 expression by CD3(+) T cells in peripheral blood after GD2-BsAb or HER2-BsAb treatment. $\mathbf{c} \| \mathrm{HC}$ staining and flow cytometry analysis of human PD-L1 in osteosarcoma 143B xenografts. PD-L1 expression levels were quantified using geometric MFI (MFI)

growths compared to GD2-EATs alone $(P=0.0149)$. While none of the anti-PD-1 combination regimens did improve survival over GD2-EATs, SCT of anti-PD-L1 did improve the survival of the mice compared to GD2-EATs alone $(P=0.0009)$.

To address the effect of PD-1 blockades on T cell infiltration into tumors, we harvested tumors when they reached $2000 \mathrm{~mm}^{3}$ or on the last day of the experiment. TILs were analyzed by flow cytometry (Additional file 2 : Fig.S4A). GD2-EATs recruited more $\mathrm{T}$ cells into the tumors compared to unarmed $\mathrm{T}$ cells $(P=0.0295)$ or anti-PD-1 plus unarmed T cells $(P=0.0236)$. CT of antiPD-1 resulted in fewer TILs than GD2-EATs $(P=0.0194)$. With ST regimen, anti-PD-1 showed comparable TIL frequency with GD2-EATs $(P=0.54)$; with SCT regimen, anti-PD-1 increased TIL frequency over GD2-EATs alone $(P=0.0056)$ (Additional file 2: Fig. S4B). On the other hand, CT of anti-PD-L1 did not affect TIL frequencies of GD2-EATs $(P=0.8815)$, but ST and SCT of antiPD-L1 increased TIL frequencies over GD2-EATs alone $(P=0.0018$ and $P=0.0005)$ (Additional file 2 Fig.S3C). Among the TIL subsets, tumors treated with SCT regimen (irrespective of anti-PD-1 or anti-PD-L1) had significantly greater frequencies of $\mathrm{CD} 8(+) \mathrm{T}$ cells compared to GD2-EATs alone $(P<0.0001)$. The difference in TIL frequencies among groups was confirmed by IHC staining using anti-CD3 antibody (Fig. 5b). Anti-PD-L1 combinations significantly increased $\mathrm{CD} 3(+) \mathrm{T}$ cell numbers in tumors compared to GD2-EATs alone $(P<0.0001)$ and consistently had greater frequencies of TILs than antiPD-1 combinations, providing a rationale for combining with anti-PD-L1 rather than anti-PD-1 for synergy with BsAb-based T cell immunotherapy.

\section{Discussion}

Osteosarcoma tissues overexpress GD2 and HER2 on their surface, and these antigens targeting strategies have been a subject of great attention. However, clinical trials of anti-HER2 trastuzumab or anti-GD2 dinutuximab for metastatic or refractory osteosarcoma were not successful $[38,39]$. This failure attributed to relatively low expression levels of GD2 or HER2 on osteosarcoma tumor tissues [40], or inherent insensitivity of this tumor to Fc-dependent immune cytotoxic mechanisms [41, 42]. In this study, we targeted these antigens using $\mathrm{T}$ cell engaging BsAb and studied the anti-tumor effect of
GD2-BsAb and HER2-BsAb against osteosarcoma. Both BsAbs successfully directed $\mathrm{T}$ cells into tumor tissues and exerted a significant anti-tumor effect. T cells armed with GD2-BsAb or HER2-BsAb showed potent tumorsuppressive effect in a variety of osteosarcoma xenograft mouse models with minimal in vivo toxicities. Moreover, osteosarcoma PDX-bearing mice showed long-term cures after GD2-EATs and HER2-EATs treatment, consistent with their high potency, although xenogeneic GVHD effect or epitope spread among long-term memory $\mathrm{T}$ cells in vivo cannot be ruled out $[37,43,44]$. The use of bispecific murine antibodies in syngeneic mouse models will help address these potential mechanisms of tumor control.

To improve therapeutic efficacy of GD2-EATs and HER2-EATs, combination with PD-1 blockades was tested. CD8(+) TILs in metastatic osteosarcoma tissues overexpressed PD-1, and PD-1/PD-L1 blockades partially improved $\mathrm{T}$ cell function, resulting in longer survival with fewer pulmonary metastases in previous studies [18]. However, how to optimally combine ICIs with other immunotherapies has yet to be determined, given the potential negative impact of the concurrent use of immunotherapeutics $[45,46]$. Our data also showed that concurrently administered anti-PD-1 or anti-PD-L1 had no benefit. Sequentially continuous anti-PD-L1 only did improve the anti-tumor effect of GD2-EATs against osteosarcoma. It suggests that continuous neutralization of PD-L1 may be necessary for optimal synergy with BsAb and $\mathrm{T}$ cell immunotherapy.

Although cytotoxic CD8(+) $\mathrm{T}$ cells mediate direct tumor cell killing, $\mathrm{CD} 4(+) \mathrm{T}$ helper $(\mathrm{TH})$ cells are also important in tumor cell eradication [47], as CD4(+) CAR $\mathrm{T}$ cells exert significant cytotoxicity comparable to CD8(+) CAR T cells [48]. According to recently published single-cell analysis data, both CD4(+) TH cells and $\mathrm{CD} 8(+)$ cytotoxic $\mathrm{T}$ cells are equally effective in direct tumor cell killing, and their cytotoxicity is associated with both TH1 and TH2 cytokines, e.g., IFN- $\gamma$, TNF- $\alpha$, IL-15, and IL-13, as confirmed by the expression of master transcription factor genes TBX21 and GATA3 [49, 50]. In addition, rather than stringent $\mathrm{TH} 1$ or $\mathrm{TH} 2$ subtypes, the predominant anti-tumor response is dependent on a highly mixed TH1/TH2 function in the same cell, suggesting the activation of BsAb-directed $\mathrm{T}$ cells or CAR $\mathrm{T}$ cells is a canonical process that leads to a 
a
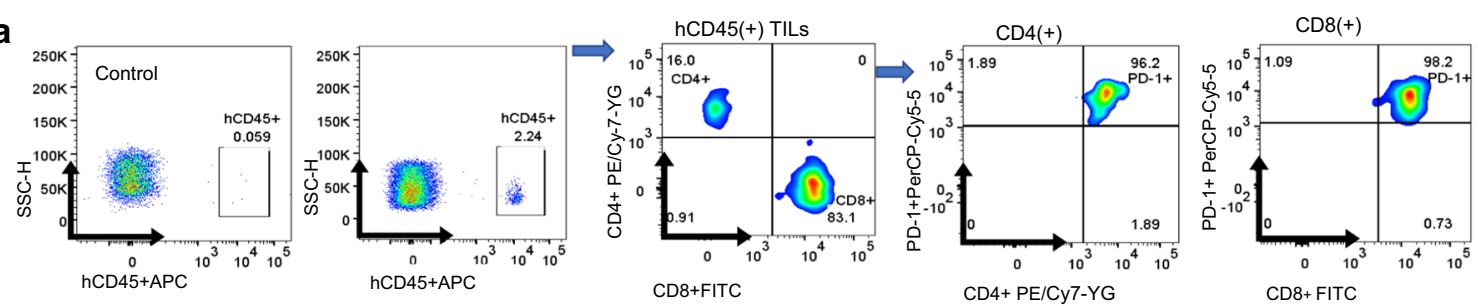

b
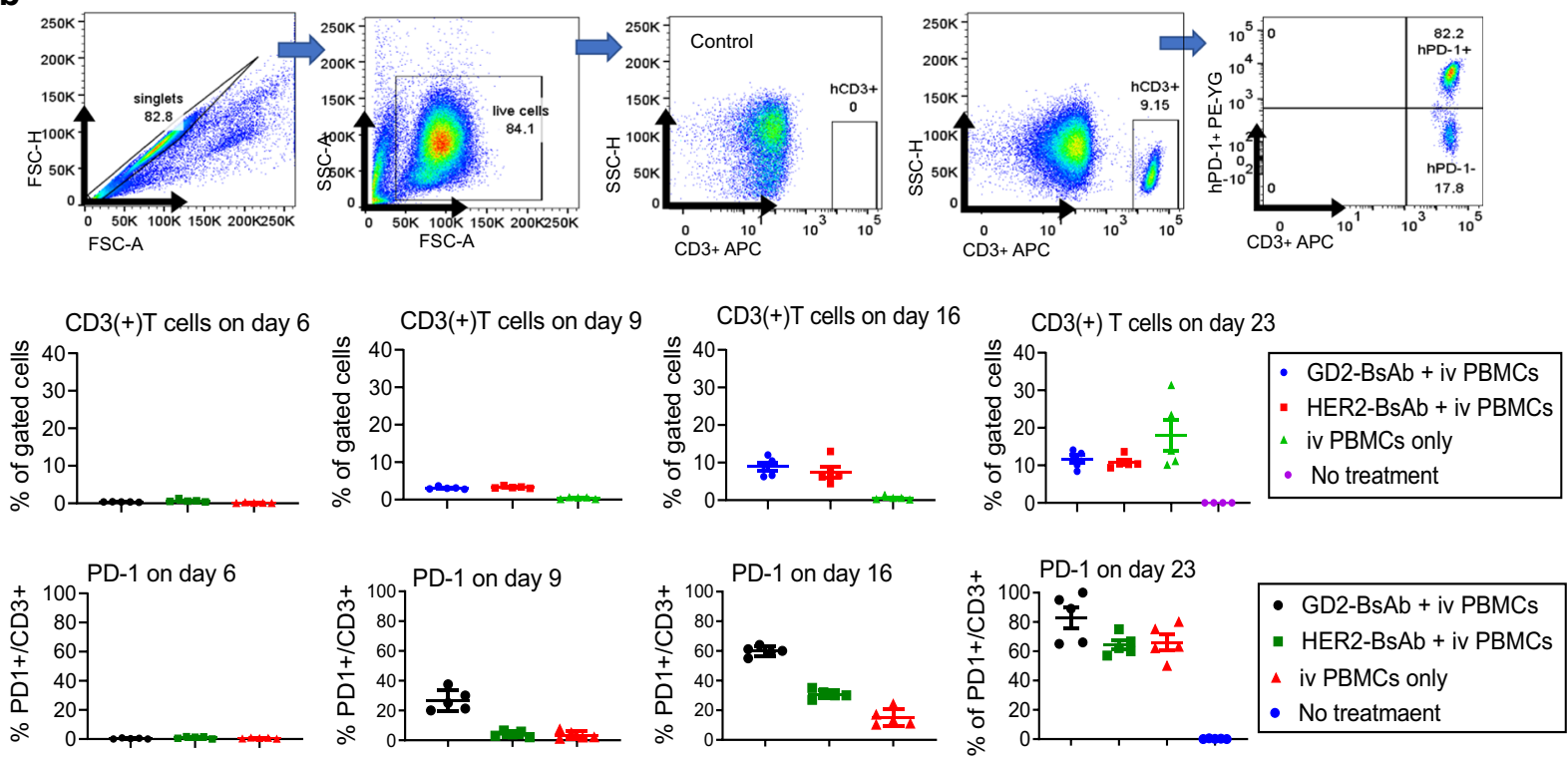

- GD2-BsAb + iv PBMCs

- HER2-BsAb + iv PBMCs

$\Delta$ iv PBMCs only

- No treatmaent

\section{C}

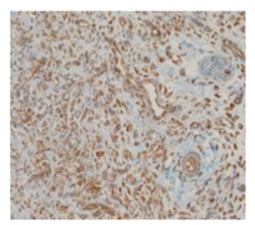

No treatment

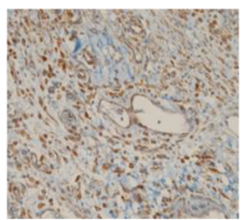

Iv GD2-BsAb

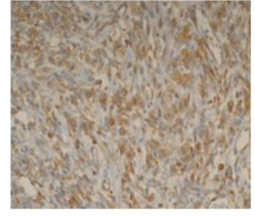

Iv HER2-BsAb
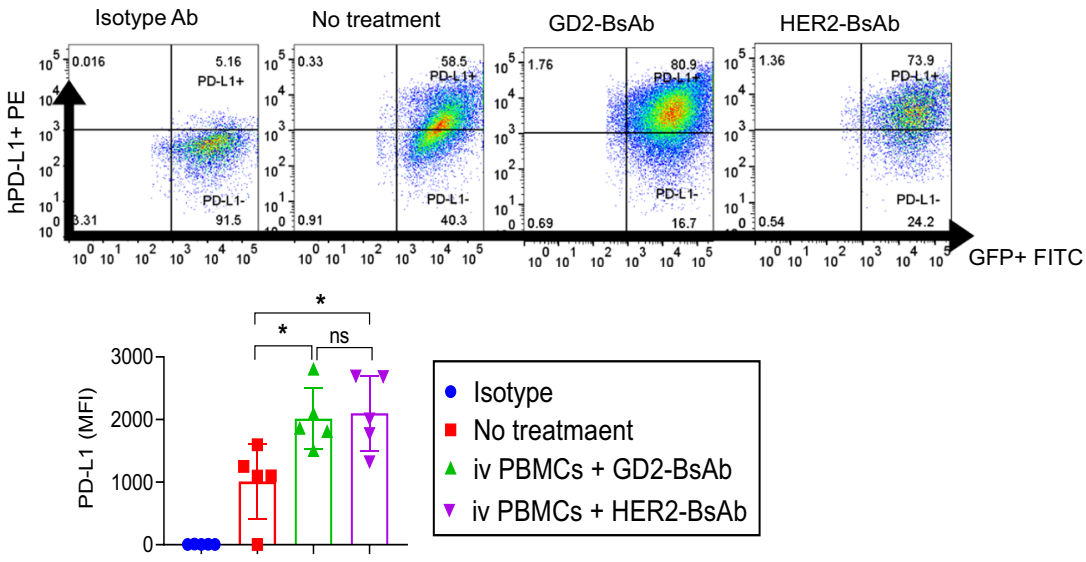


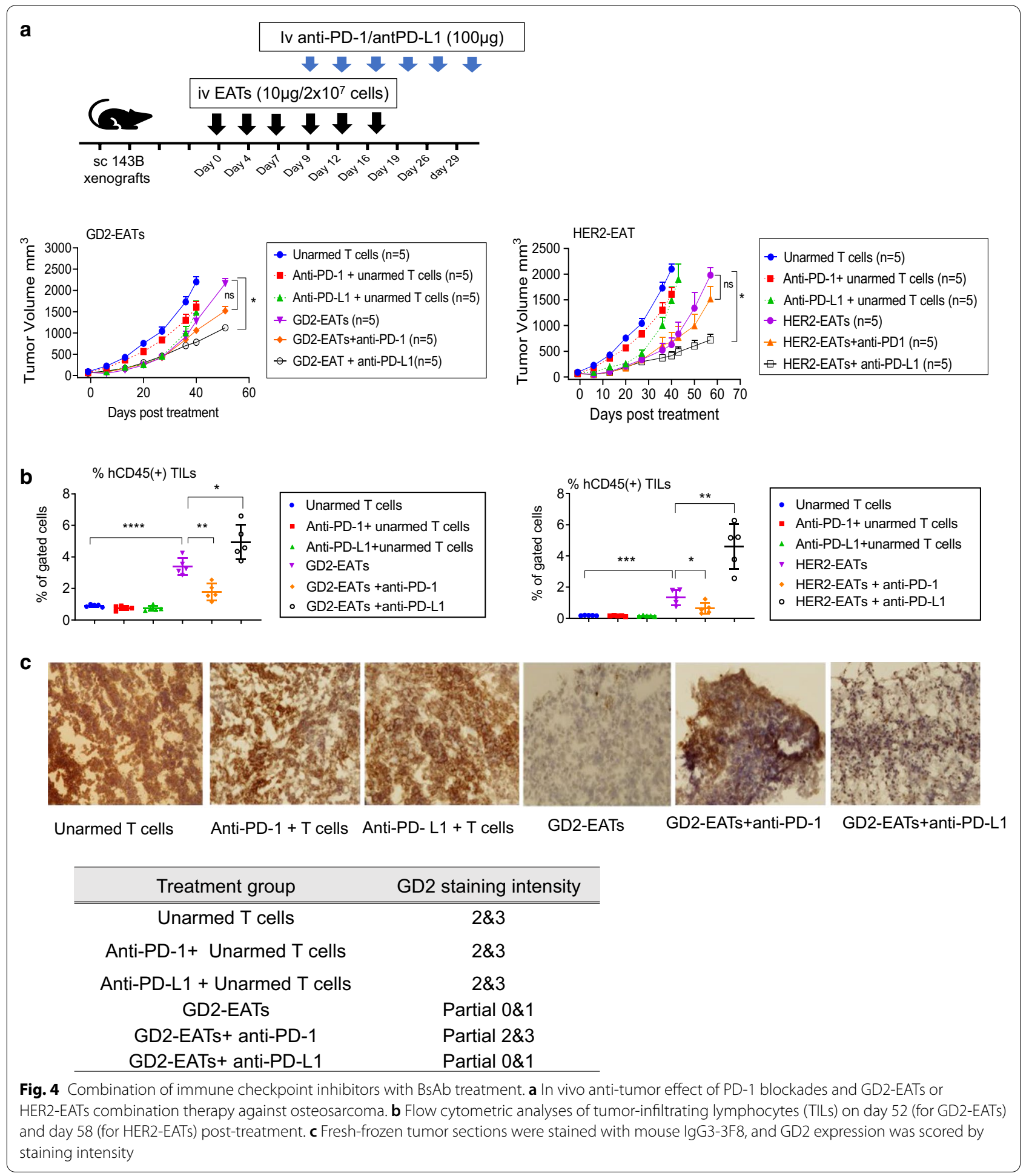

mixed response combining both $\mathrm{TH} 1$ and $\mathrm{TH} 2$ cytokines together with GM-CSF [49]. This is consistent with the finding that polyfunctional CAR T cells are highly correlated to objective response of patients [51]. On the other hand, the ratio of $\mathrm{CD} 4(+)$ to $\mathrm{CD} 8(+) \mathrm{T}$ cells does have an effect on the anti-tumor activity of CAR T cells [52, 53]. Furthermore, balanced ratio of $\mathrm{CD} 4(+)$ and $\mathrm{CD} 8(+)$ CAR $T$ cells (CD4:CD8 ratio 1:1) seemed to be important for high remission rates in B-ALL [51]. CD4 $(+)$ T cells help $\mathrm{CD} 8(+) \mathrm{T}$ cells differentiate, recruit and expand 


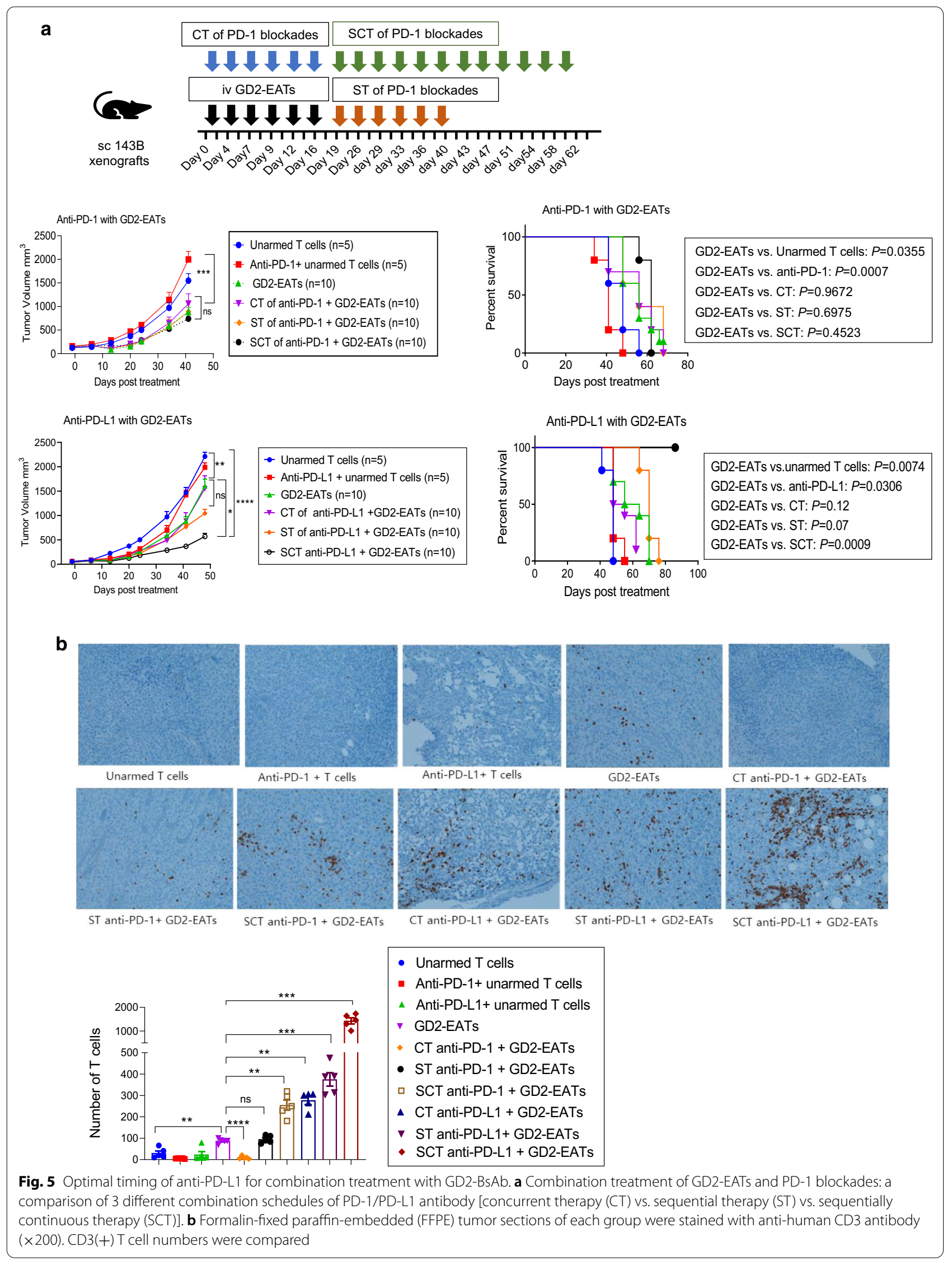


through IL-2, IL-21 and other cytokines to perform their tumoricidal functions $[54,55]$. CD4(+) T cells in tumorous condition or chronic infection are skewed toward the $\mathrm{T}$ follicular helper (TFH) phenotype $[56,57]$. While the majority of exhausted $\mathrm{T}$ cells in tumors express intermediate levels of PD-1, TFH cells express high levels of PD-1, not predictive of patient survival $[58,59]$. The in vivo anti-tumor effect was likely dependent on both CD4(+) T cells and CD8(+) T cells, as our serial IHC data (Fig. 1d) did suggest a temporal sequence where the initial arrival of CD4(+) T cells was followed by subsequent infiltration of CD8(+) T cells. In this regard, temporal and spatial distributions of $\mathrm{PD}-1(+) \mathrm{CD} 4(+) \mathrm{T}$ cells might be susceptible to concurrently administered anti-PD-1.

On the other hand, the benefit of anti-PD-L1 was predicted by the expression of tumor-associated PD-L1 (B7-H1) by osteosarcoma cell lines. When confronted by tumor targets, EATs produce pro-inflammatory cytokines such as IFN- $\gamma$, upregulating PD-L1, which induces $\mathrm{T}$ cell apoptosis and inhibits $\mathrm{T}$ cell cytotoxicity [60]. Activation-induced T cell death (AICD), associated with IL-10 and Fas/FasL interaction [61], is a component of PD-L1-mediated $\mathrm{T}$ cell apoptosis and can be prevented by anti-PD-L1, but not by anti-PD-1 [60].

In addition, surface proteomic analysis of osteosarcoma has identified a wide range of proteins with differential abundance on osteosarcoma cells and human primary osteoblasts including ephrin type-A receptor (EPHA2) [62]. Using bioinformatics to assess the expression of surface target antigens on osteosarcoma could provide alternative promising strategy to discover new target antigens for $\mathrm{T}$ cell immunotherapies including BsAb and CAR [63, 64].

In conclusion, targeted $\mathrm{T}$ cell therapy using GD2-BsAb or HER2-BsAb enabled effective $T$ cell infiltration into tumors and exerted potent anti-tumor activity against osteosarcoma. GD2-EATs and HER2-EATs were also effective to treat osteosarcoma xenografts with reduced toxicity. When GD2-BsAb and HER2-BsAb were combined with anti-PD-L1, tumors had more T cells inside, especially when anti-PD-L1 was continued post-GD2$\mathrm{BsAb}$ treatment. These data strongly support the clinical applicability of GD2- and HER2-BsAbs and the sequentially continuous combination of anti-PD-L1 antibody for the treatment of osteosarcoma.

\section{Supplementary information}

The online version contains supplementary material available at https://doi. org/10.1186/s13045-020-01012-y.

Additional file 1: Table S1. Purity, binding affinity and endotoxin of bispecific antibodies.
Additional file 2: Figure S1. (A) Representative flow cytometry analysis of tumor-associated target antigens in the osteosarcoma U-2 OS cell line. GD2, disialoganglioside; GD3, disialohematoside; HER2, human epidermal growth factor receptor 2; CSPG4, Chondroitin-sulfate proteoglycan 4; GPA, glycoprotein A33; L1CAM, L1 cell adhesion molecule; GPC-3, glypican-3; PSA, polysialic acid; PD-L1, programmed death-ligand 1; PSMA, prostatespecific membrane antigen; IGF2R; Insulin-like growth factor 2 receptor. Figure S2. (A) The geometric mean fluorescence intensities (MFIs) of GD2BsAb and HER2-BsAb bound to EATs were measured using anti-idiotype or anti-human IgG Fc antibody. (B) Antibody-dependent T cell-mediated cytotoxicity assay (ADTC) using GD2-EATs and HER2-EATs at decreasing ET (effector to target) ratios and decreasing BsAb arming concentrations. (C) MFIs of GD2-EAT and HER2-EAT over time in flow cytometry. $1 \times 10^{6}$ of T cells were armed with $0.5 \mu \mathrm{g}$ of GD2-BsAb (GD2-EAT) or HER2-BsAb (HER2-EATs) and measured the MFIs by APC-conjugated anti-human IgG Fc antibody. GD2-EATs and HER2-EATs were incubated at $4^{\circ} \mathrm{C}$, and the MFIs of the live cells were analyzed at each time point. Figure S3. In vivo cytokine release by GD2-EATs. (A) Plasma TH1 cell cytokines including IL-2, IL-6, IL-10, TNF-a, and IFN- $\gamma$ were measured after 4 hours of EAT treatment and compared among groups. (B) Plasma TH1 cell cytokine levels were analyzed at $4 \mathrm{hrs}, 12 \mathrm{hrs}$, and 24 hours post-GD2-EAT treatment. The $P$ values of AUC for plasma cytokine levels were analyzed. Figure S4. (A) Flow cytometry analyses of tumor infiltrating lymphocytes (TILs). (B) Comparison of TIL frequencies among groups treated with different combination schedules of anti-PD-1 antibody and GD2-EATs. (C) Comparison of the TIL frequencies among groups treated with different combination schedules of anti-PD-L1 antibody and GD2-EATs.

\section{Abbreviations}

ATCs: Activated T cells; AICD: Activation-induced T cell death; ADTC: Antibodydependent T cell-mediated cytotoxicity; AUC: Area under curve; BRG: BALB-Rag2 $2^{-1-I L-2 R-\gamma C-K O ; ~ C A R: ~ C h i m e r i c ~ a n t i g e n ~ r e c e p t o r ; ~ C S P G 4: ~ C h o n-~}$ droitin-sulfate proteoglycan-4; CT: Concurrent therapy; CRS: Cytokine release syndrome; GD2: Disialogangliosides; ET ratio: Effector-to-target cells ratio; EATs: Ex vivo BsAb-armed T cells; MFI: Geometric mean fluorescence intensity; GPC-3: Glypican-3; HMW-M: High molecular weight melanoma antigen; HER2: Human epidermal growth factor receptor 2; ICls: Immune checkpoint inhibitors; IHC: Immunohistochemistry; IGF2R: Insulin-like growth factor 2 receptor; IL-11 Ra: Interleukin 11 receptor-a; L1CAM: L1 cell adhesion molecule; PDXs: Patient-derived xenografts; PBMC: Peripheral blood mononuclear cells; PD-L1: Programmed cell death-1 receptor ligand-1; PD-1: Programmed cell death-1 receptor; PSA: Prostate-specific antigen; PSMA: Prostate-specific membrane antigen; ST: Sequential therapy; SCT: Sequentially continuous therapy; T-BsAbs: T cell engaging bispecific antibodies; TFH: T follicular helper cell; TILs: Tumor-infiltrating lymphocytes.

\section{Acknowledgements}

We would like to especially thanks to Irene Cheung, Alan W. Long, Brian Santich, Madelyne Epinosa-Cotton, Mao Wang, See Liang Ng, Tsung-Yi Lin, and Xu Hong for their valuable comments on earlier drafts. Xu Hong designed and validated the anti-HER2 BsAb and analyzed BsAb affinity to CD3 and each target antigen. Hong-fen Guo did HPLC and SDS-PAGE and confirmed the purity and stability of each BsAb. Yi Feng stained fresh-frozen tumor sections.

\section{Authors' contributions}

JAP and N-KVC designed the experiments, interpreted, and analyzed the results and wrote the manuscript. All authors reviewed this manuscript and approved the final manuscript.

\section{Funding}

This work was supported by funds from Enid A. Haupt Endowed Chair, the Robert Steel Foundation, Kids Walk for Kids with Cancer, as well as sponsored research fund from Y-mAbs Therapeutics. Technical service provided by the MSK Animal Imaging Core Facility, Antitumor Assessment Core Facility, and Molecular Cytology Core Facility were supported in part by the NCI Cancer Center Support Grant P30 CA008748. 


\section{Availability of data and materials}

All data generated or analyzed during this study are included in this published article or uploaded as supplementary information.

\section{Ethics approval and consent to participate}

All animal experiments were approved by the Memorial Sloan Kettering's Institutional Animal Care and Use Committee (IACUC) and were executed according to the ACUC guidelines. Patient-derived tumor xenografts were established with MSKCC IRB approval.

\section{Consent for publication}

\section{Not applicable.}

\section{Competing interests}

NKC reports receiving commercial research grants from Y-mabs Therapeutics and Abpro-Labs Inc.; holding ownership interest/equity in Y-Mabs Therapeutics Inc., holding ownership interest/equity in Abpro-Labs, and owning stock options in Eureka Therapeutics. NKC is the inventor and owner of issued patents licensed by MSK to Ymabs Therapeutics, Biotec Pharmacon, and Abprolabs. Hu3F8 and 8H9 were licensed by MSK to Y-mabs Therapeutics. Both MSK and NKC have financial interest in Y-mabs. NKC is an advisory board member for Abpro-Labs and Eureka Therapeutics. JP has no disclosures to report.

\section{Received: 30 October 2020 Accepted: 25 November 2020}

\section{Published online: 10 December 2020}

\section{References}

1. Roberts RDWM, Setty BA. Chemotherapy regimens for patients with newly diagnosed malignant bone tumors. Cambridge: Springer; 2015.

2. Aljubran AH, Griffin A, Pintilie M, Blackstein M. Osteosarcoma in adolescents and adults: survival analysis with and without lung metastases. Ann Oncol. 2009;20(6):1136-41.

3. Boye K, Del Prever AB, Eriksson M, Saeter G, Tienghi A, Lindholm P, Fagioli F, Skjeldal S, Ferrari S, Hall KS. High-dose chemotherapy with stem cell rescue in the primary treatment of metastatic and pelvic osteosarcoma: final results of the ISG/SSG II study. Pediatr Blood Cancer. 2014;61(5):840-5.

4. Allison DC, Carney SC, Ahlmann ER, Hendifar A, Chawla S, Fedenko A, Angeles C, Menendez LR. A meta-analysis of osteosarcoma outcomes in the modern medical era. Sarcoma. 2012;2012:704872.

5. Coley WB. The treatment of inoperable sarcoma by bacterial toxins (the mixed toxins of the streptococcus erysipelas and the Bacillus prodigiosus). Proc R Soc Med. 1910;3(1):1-48.

6. Muller CR, Smeland S, Bauer HC, Saeter G, Strander H. Interferon-alpha as the only adjuvant treatment in high-grade osteosarcoma: long term results of the Karolinska Hospital series. Acta Oncol. 2005;44(5):475-80.

7. Meyers PA, Schwartz CL, Krailo MD, Healey JH, Bernstein ML, Betcher D, Ferguson WS, Gebhardt MC, Goorin AM, Harris M, et al. Osteosarcoma: the addition of muramyl tripeptide to chemotherapy improves overal survival - a report from the Children's Oncology Group. J Clin Oncol. 2008;26(4):633-8.

8. Bielack SS, Smeland S, Whelan JS, Marina N, Jovic G, Hook JM, Krailo MD, Gebhardt M, Papai Z, Meyer J, et al. Methotrexate, doxorubicin, and cisplatin (MAP) plus maintenance pegylated interferon alfa-2b versus MAP alone in patients with resectable high-grade osteosarcoma and good histologic response to preoperative MAP: first results of the EURAMOS-1 good response randomized controlled trial. J Clin Oncol. 2015;33(20):2279-87.

9. Wu CC, Beird HC, Andrew Livingston J, Advani S, Mitra A, Cao S, Reuben A, Ingram D, Wang WL, Ju Z, et al. Immuno-genomic landscape of osteosarcoma. Nat Commun. 2020;11(1):1008.

10. Chen X, Bahrami A, Pappo A, Easton J, Dalton J, Hedlund E, Ellison D, Shurtleff S, Wu G, Wei L, et al. Recurrent somatic structural variations contribute to tumorigenesis in pediatric osteosarcoma. Cell Rep. 2014;7(1):104-12.

11. Perry JA, Kiezun A, Tonzi P, Van Allen EM, Carter SL, Baca SC, Cowley GS, Bhatt AS, Rheinbay E, Pedamallu CS, et al. Complementary genomic approaches highlight the PI3K/mTOR pathway as a common vulnerability in osteosarcoma. Proc Natl Acad Sci USA. 2014;111(51):E5564-5573.
12. Behjati S, Tarpey PS, Haase K, Ye H, Young MD, Alexandrov LB, Farndon SJ, Collord G, Wedge DC, Martincorena I, et al. Recurrent mutation of IGF signalling genes and distinct patterns of genomic rearrangement in osteosarcoma. Nat Commun. 2017:8:15936.

13. Du X, Yang J, Yang D, Tian W, Zhu Z. The genetic basis for inactivation of Wnt pathway in human osteosarcoma. BMC Cancer. 2014;14:450.

14. Grignani G, Palmerini E, Ferraresi V, D’Ambrosio L, Bertulli R, Asaftei SD, Tamburini A, Pignochino Y, Sangiolo D, Marchesi E, et al. Sorafenib and everolimus for patients with unresectable high-grade osteosarcoma progressing after standard treatment: a non-randomised phase 2 clinical trial. Lancet Oncol. 2015;16(1):98-107.

15. Martin-Broto J, Redondo A, Valverde C, Vaz MA, Mora J, Garcia Del Muro X, Gutierrez A, Tous C, Carnero A, Marcilla D, et al. Gemcitabine plus sirolimus for relapsed and progressing osteosarcoma patients after standard chemotherapy: a multicenter, single-arm phase II trial of Spanish Group for Research on Sarcoma (GEIS). Ann Oncol. 2017;28(12):2994-9.

16. Huang X, Zhang W, Zhang Z, Shi D, Wu F, Zhong B, Shao Z. Prognostic value of programmed cell death 1 ligand-1 (PD-L1) or PD-1 expression in patients with osteosarcoma: a meta-analysis. J Cancer. 2018:9(14):2525-31.

17. Palmerini E, Agostinelli C, Picci P, Pileri S, Marafioti T, Lollini PL, Scotlandi K, Longhi A, Benassi MS, Ferrari S. Tumoral immune-infiltrate (IF), PD-L1 expression and role of CD8/TIA-1 lymphocytes in localized osteosarcoma patients treated within protocol ISG-OS1. Oncotarget. 2017;8(67):111836-46.

18. Lussier DM, O'Neill L, Nieves LM, McAfee MS, Holechek SA, Collins AW, Dickman P, Jacobsen J, Hingorani P, Blattman JN. Enhanced T-cell immunity to osteosarcoma through antibody blockade of PD-1/PD-L1 interactions. J Immunother. 2015;38(3):96-106.

19. Xu H, Cheng M, Guo H, Chen Y, Huse M, Cheung NK. Retargeting T cells to GD2 pentasaccharide on human tumors using Bispecific humanized antibody. Cancer Immunol Res. 2015;3(3):266-77.

20. Lopez-Albaitero A, Xu H, Guo H, Wang L, Wu Z, Tran H, Chandarlapaty S, Scaltriti M, Janjigian Y, de Stanchina E, et al. Overcoming resistance to HER2-targeted therapy with a novel HER2/CD3 bispecific antibody. Oncoimmunology. 2017;6(3):e1267891.

21. Verma R, Foster RE, Horgan K, Mounsey K, Nixon H, Smalle N, Hughes TA Carter CR. Lymphocyte depletion and repopulation after chemotherapy for primary breast cancer. Breast Cancer Res. 2016;18(1):10.

22. Oved JH, Barrett DM, Teachey DT. Cellular therapy: Immune-related complications. Immunol Rev. 2019;290(1):114-26.

23. Yankelevich M, Kondadasula SV, Thakur A, Buck S, Cheung NK, Lum LG. Anti-CD3 $x$ anti-GD2 bispecific antibody redirects T-cell cytolytic activity to neuroblastoma targets. Pediatr Blood Cancer. 2012;59(7):1198-205.

24. Lum LG, Thakur A, Al-Kadhimi Z, Colvin GA, Cummings FJ, Legare RD, Dizon DS, Kouttab N, Maizel A, Colaiace W, et al. Targeted T-cell therapy in stage IV breast cancer: a phase I clinical trial. Clin Cancer Res. 2015;21(10):2305-14.

25. Vaishampayan U, Thakur A, Rathore R, Kouttab N, Lum LG. Phase I study of anti-CD3 $x$ anti-her2 bispecific antibody in metastatic castrate resistant prostate cancer patients. Prostate Cancer. 2015;2015:285193.

26. Orcutt KD, Ackerman ME, Cieslewicz M, Quiroz E, Slusarczyk AL, Frangioni JV, Wittrup KD. A modular lgG-scFv bispecific antibody topology. Protein Eng Des Sel. 2010;23(4):221-8.

27. Reikofski J, Tao BY. Polymerase chain reaction (PCR) techniques for sitedirected mutagenesis. Biotechnol Adv. 1992;10(4):535-47.

28. Wu Z, Guo HF, Xu H, Cheung NV. Development of a tetravalent antiGPA33/anti-CD3 bispecific antibody for colorectal cancers. Mol Cancer Ther. 2018;17(10):2164-75.

29. Hoseini SS, Guo H, Wu Z, Hatano MN, Cheung NV. A potent tetravalent T-cell-engaging bispecific antibody against CD33 in acute myeloid leukemia. Blood Adv. 2018;2(11):1250-8.

30. Andrade D, Redecha PB, Vukelic M, Qing X, Perino G, Salmon JE, Koo GC. Engraftment of peripheral blood mononuclear cells from systemic lupus erythematosus and antiphospholipid syndrome patient donors into BALB-RAG-2-/- IL-2Rgamma-/- mice: a promising model for studying human disease. Arthritis Rheum. 2011;63(9):2764-73.

31. Dobrenkov K, Ostrovnaya I, Gu J, Cheung IY, Cheung NK. Oncotargets GD2 and GD3 are highly expressed in sarcomas of children, adolescents, and young adults. Pediatr Blood Cancer. 2016;63(10):1780-5. 
32. Hassan SE, Bekarev M, Kim MY, Lin J, Piperdi S, Gorlick R, Geller DS. Cell surface receptor expression patterns in osteosarcoma. Cancer. 2012;118(3):740-9.

33. Shibuya $H$, Hamamura $K$, Hotta H, Matsumoto $Y$, Nishida $Y$, Hattori $H$, Furukawa K, Ueda M, Furukawa K. Enhancement of malignant properties of human osteosarcoma cells with disialyl gangliosides GD2/GD3. Cancer Sci. 2012;103(9):1656-64.

34. Schwab JH, Boland PJ, Agaram NP, Socci ND, Guo T, O'Toole GC, Wang X, Ostroumov E, Hunter CJ, Block JA, et al. Chordoma and chondrosarcoma gene profile: implications for immunotherapy. Cancer Immunol Immunother. 2009;58(3):339-49.

35. Torabi A, Amaya CN, Wians FH Jr, Bryan BA. PD-1 and PD-L1 expression in bone and soft tissue sarcomas. Pathology. 2017;49(5):506-13.

36. Pearson T, Greiner DL, Shultz LD: Creation of "humanized" mice to study human immunity. Curr Protoc Immunol 2008, Chapter 15:Unit 15.21.

37. Ali N, Flutter B, Sanchez Rodriguez R, Sharif-Paghaleh E, Barber LD, Lombardi G, Nestle FO. Xenogeneic graft-versus-host-disease in NOD-scid IL-2Rgammanull mice display a T-effector memory phenotype. PLoS ONE. 2012;7(8):e44219.

38. Ebb D, Meyers P, Grier H, Bernstein M, Gorlick R, Lipshultz SE, Krailo M, Devidas M, Barkauskas DA, Siegal GP, et al. Phase II trial of trastuzumab in combination with cytotoxic chemotherapy for treatment of metastatic osteosarcoma with human epidermal growth factor receptor 2 overexpression: a report from the children's oncology group. J Clin Oncol. 2012;30(20):2545-51.

39. Yu AL, Uttenreuther-Fischer MM, Huang CS, Tsui CC, Gillies SD, Reisfeld RA, Kung FH. Phase I trial of a human-mouse chimeric anti-disialoganglioside monoclonal antibody ch 14.18 in patients with refractory neuroblastoma and osteosarcoma. J Clin Oncol. 1998;16(6):2169-80.

40. Somers GR, Ho M, Zielenska M, Squire JA, Thorner PS. HER2 amplification and overexpression is not present in pediatric osteosarcoma: a tissue microarray study. Pediatr Dev Pathol. 2005;8(5):525-32.

41. Ullenhag GJ, Spendlove I, Watson NF, Kallmeyer C, Pritchard-Jones K, Durrant LG. T-cell responses in osteosarcoma patients vaccinated with an anti-idiotypic antibody, 105AD7, mimicking CD55. Clin Immunol. 2008;128(2):148-54

42. Sundara YT, Kostine M, Cleven AH, Bovee JV, Schilham MW, CletonJansen AM. Increased PD-L1 and T-cell infiltration in the presence of HLA class I expression in metastatic high-grade osteosarcoma: a rationale for T-cell-based immunotherapy. Cancer Immunol Immunother. 2017:66(1):119-28.

43. Menares E, Gálvez-Cancino F, Cáceres-Morgado P, Ghorani E, López E, Díaz X, Saavedra-Almarza J, Figueroa DA, Roa E, Quezada SA, et al. Tissueresident memory CD8. Nat Commun. 2019;10(1):4401.

44. Vanderlugt CL, Miller SD. Epitope spreading in immune-mediated diseases: implications for immunotherapy. Nat Rev Immunol. 2002;2(2):85-95.

45. Shrimali RK, Ahmad S, Verma V, Zeng P, Ananth S, Gaur P, Gittelman RM, Yusko E, Sanders C, Robins H, et al. Concurrent PD-1 blockade negates the effects of OX40 agonist antibody in combination immunotherapy through inducing T-cell apoptosis. Cancer Immunol Res. 2017;5(9):755-66.

46. Messenheimer DJ, Jensen SM, Afentoulis ME, Wegmann KW, Feng Z, Friedman DJ, Gough MJ, Urba WJ, Fox BA. Timing of PD-1 blockade is critical to effective combination immunotherapy with anti-OX40. Clin Cancer Res. 2017;23(20):6165-77.

47. Wang D, Aguilar B, Starr R, Alizadeh D, Brito A, Sarkissian A, Ostberg JR, Forman SJ, Brown CE: Glioblastoma-targeted CD4+ CART cells mediate superior antitumor activity. JCI Insight 2018, 3(10).
48. Yang Y, Kohler ME, Chien CD, Sauter CT, Jacoby E, Yan C, Hu Y, Wanhainen K, Qin H, Fry TJ: TCR engagement negatively affects CD8 but not CD4 CAR T cell expansion and leukemic clearance. Sci Transl Med 2017, 9(417).

49. Xhangolli I, Dura B, Lee G, Kim D, Xiao Y, Fan R. Single-cell analysis of CAR-T cell activation reveals a mixed T. Genomics Proteomics Bioinform. 2019;17(2):129-39.

50. Szabo PA, Levitin HM, Miron M, Snyder ME, Senda T, Yuan J, Cheng YL, Bush EC, Dogra P, Thapa P, et al. Single-cell transcriptomics of human T cells reveals tissue and activation signatures in health and disease. Nat Commun. 2019;10(1):4706.

51. Turtle CJ, Hanafi LA, Berger C, Gooley TA, Cherian S, Hudecek M, Sommermeyer D, Melville K, Pender B, Budiarto TM, et al. CD19 CAR-T cells of defined CD4+:CD8+ composition in adult B cell ALL patients. J Clin Invest. 2016;126(6):2123-38.

52. Stock S, Schmitt M, Sellner L: Optimizing manufacturing protocols of chimeric antigen receptor $T$ cells for improved anticancer immunotherapy. Int J Mol Sci 2019, 20(24).

53. Sommermeyer D, Hudecek M, Kosasih PL, Gogishvili T, Maloney DG, Turtle CJ, Riddell SR. Chimeric antigen receptor-modified T cells derived from defined CD8+ and CD4+ subsets confer superior antitumor reactivity in vivo. Leukemia. 2016;30(2):492-500.

54. Swain SL, McKinstry KK, Strutt TM. Expanding roles for CD4(+) T cells in immunity to viruses. Nat Rev Immunol. 2012;12(2):136-48.

55. Cox MA, Harrington LE, Zajac AJ. Cytokines and the inception of CD8 T cell responses. Trends Immunol. 2011;32(4):180-6.

56. Kim HJ, Cantor H. CD4 T-cell subsets and tumor immunity: the helpful and the not-so-helpful. Cancer Immunol Res. 2014;2(2):91-8.

57. Ma CS, Deenick EK. Human T follicular helper (Tfh) cells and disease. Immunol Cell Biol. 2014;92(1):64-71.

58. Onabajo OO, George J, Lewis MG, Mattapallil JJ. Rhesus macaque lymph node PD-1 (hi)CD4+ T cells express high levels of CXCR5 and IL-21 and display a CCR7(lo)ICOS+Bcl6+T-follicular helper (Tfh) cell phenotype. PLoS ONE. 2013;8(3):e59758.

59. Yang ZZ, Grote DM, Ziesmer SC, Xiu B, Novak AJ, Ansell SM. PD-1 expression defines two distinct T-cell sub-populations in follicular lymphoma that differentially impact patient survival. Blood Cancer J. 2015;5:e281.

60. Dong H, Strome SE, Salomao DR, Tamura H, Hirano F, Flies DB, Roche PC, Lu J, Zhu G, Tamada K, et al. Tumor-associated B7-H1 promotes T-cell apoptosis: a potential mechanism of immune evasion. Nat Med. 2002;8(8):793-800

61. Nagata S, Golstein P. The Fas death factor. Science. 1995;267(5203):1449-56.

62. Posthumadeboer J, Piersma SR, Pham TV, van Egmond PW, Knol JC, Cleton-Jansen AM, van Geer MA, van Beusechem VW, Kaspers GJ, van Royen BJ, et al. Surface proteomic analysis of osteosarcoma identifies EPHA2 as receptor for targeted drug delivery. Br J Cancer. 2013;109(8):2142-54

63. Xiang $Y, Y$, Y, Zhang Z, Han L. Maximizing the utility of cancer transcriptomic data. Trends Cancer. 2018;4(12):823-37.

64. Sahin U, Koslowski M, Dhaene K, Usener D, Brandenburg G, Seitz G, Huber C, Türeci O. Claudin-18 splice variant 2 is a pan-cancer target suitable for therapeutic antibody development. Clin Cancer Res. 2008;14(23):7624-34.

\section{Publisher's Note}

Springer Nature remains neutral with regard to jurisdictional claims in published maps and institutional affiliations. 